\title{
Features of digital socialization of primary school students in the context of different levels of Internet involvement
}

\section{Características de la socialización digital de estudiantes de primaria en el contexto de diferentes niveles de participación en Internet}

\author{
Angelina N. Pronina* \\ Bunin Yelets State University, Yelets, Russian Federation. \\ ORCID: http://orcid.org/0000-0001-5454-9830 \\ Vera S. Merenkova \\ Bunin Yelets State University, Yelets, Russian Federation. \\ ORCID: http://orcid.org/0000-0003-1550-3746 \\ Stanislav E. Popov \\ Bunin Yelets State University, Yelets, Russian Federation. \\ ORCID: http://orcid.org/0000-0002-1957-8158
}

Received 06-12-20 Revised 07-25-20 Accepted 09-13-20 On line 09-22-20

*Correspondence

Email: angelicapronina@yandex.ru
Cite as:

Pronina, A.N., Merenkova, V.S., Popov, S.E. (2020) Features of digital socialization of primary school students in the context of different levels of Internet involvement. Propósitos y Representaciones, 8 (SPE3), e713. Doi: http://dx.doi.org/10.20511/pyr2020.v8nSPE3.713 


\section{Summary}

Nowadays, human life is greatly influenced by digitalization and informatization, which requires the reinterpretation of the matter of social formation and human development in the context of ontogenesis. From the moment of birth, a child lives in a mixed social and digital environment, which influences traditional socialization in one way or another. The researchers identify both positive and negative aspects of digital socialization of the younger generation. The authors of the present research analyzed the features of digital socialization of primary school students with different levels of Internet involvement. The experiment on the identification of Internet addiction involved 540 parents. The sample on the study of digital socialization included 316 primary school students aged 7 to 9 . On the one hand, the results showed the preservation and demonstration of the content and methods of traditional socialization among younger students of all levels of Internet involvement in terms of digital socialization. This fact indicates the integration and combination of digital and traditional socialization. On the other hand, the increase in the levels of Internet involvement contributes to the replacement and transition from traditional socialization to a digital one.

Keywords: Socialization; Digital Socialization; Primary School Students; Internet Involvement; Internet Communication.

\section{Resumen}

Hoy en día, la vida humana está muy influenciada por la digitalización y la informatización, lo que requiere la reinterpretación de la cuestión de la formación social y el desarrollo humano en el contexto de la ontogénesis. Desde el momento del nacimiento, un niño vive en un entorno social y digital mixto, que influye en la socialización tradicional de una forma u otra. Los investigadores identifican aspectos positivos y negativos de la socialización digital de la generación más joven. Los autores de la presente investigación analizaron las características de la socialización digital de estudiantes de primaria con diferentes niveles de participación en Internet. El experimento sobre la identificación de la adicción a Internet involucró a 540 padres. La muestra en el estudio de la socialización digital incluyó a 316 estudiantes de primaria de 7 a 9 años. Por un lado, los resultados mostraron la preservación y demostración del contenido y los métodos de socialización tradicional entre los estudiantes más jóvenes de todos los niveles de participación en Internet en términos de socialización digital Este hecho indica la integración y combinación de socialización digital y tradicional. Por otro lado, el aumento en los niveles de participación en Internet contribuye al reemplazo y la transición de la socialización tradicional a la digital.

Palabra clave: Socialización; Socialización Digital; Estudiantes de Primaria; Participación en Internet; Comunicación por Internet.

\section{Introduction}

The impact of the Internet, digitalization and informatization on the economy, politics, education and other spheres of human life has caused a review and reinterpretation of the existing paradigms and provisions of natural human development. All issues related to human development in modern conditions should be considered only in coherence and in terms of the influence of the digital environment and information technology. This approach provided the introduction of new concepts and scientific areas of research, such as human development in a digital and virtual environment, digital personality, digital socialization, clip thinking, etc. According to the reports of the Global Agencies "We Are Social" and "Hootsuite" on the global state of digital technologies in 2019, it was found that Internet audience comprised 4.39 billion people in 2019, which is 366 million (9\%) more than in January 2018; social networks involved 3.48 billion registered users, which is 288 million (9\%) more than at the beginning of the last year (Global Digital Report, 2019). 
In this regard, the most significant and acute problems are development and socialization, since from the moment of birth, an individual lives in the digital space where informational technologies act as socialization agents alongside the family. "It is necessary to consider a new generation that can be referred to as the digital generation, the existence of which is highly dependent on the opportunities provided by digital technologies" (Baldiņš, 2016).

Recently, various concepts have appeared in psychological and pedagogical science, in particular, "digital socialization," "informational socialization," and "digital childhood." Digital socialization is a process mediated by all available digital technologies. Its goal is for a person to master and perceive the social experience acquired in online contexts, to regenerate this experience in a mixed offline/online reality, and to develop a digital identity as part of a real personality. Therefore, natural socialization of a personality by means of the life context is combined with a digital model of socialization and is sometimes excluded and replaced by it. Nowadays, digital socialization complements traditional socialization, and is an important part of it, while a developing digital culture complements offline, everyday culture (Soldatova, 2018).

Scientific works indicate that socialization is a situational process that is influenced by both objective, controlled and subjective, uncontrolled factors. Available data indicate the influence of the digital environment (informational and Internet technologies) on the development of social behavior models of the younger generation (Frolova and Obraztsova, 2019; Zizek, 2017). The following negative characteristics of this influence have been revealed:

- A more informal communication style develops;

- Proper names are not important;

- Communication focuses on the information exchange rather than on the participants;

- Virtual communication becomes more superficial and less humanitarian, putting emotional interrelations at risk;

- Communication becomes more superficial and less humane, jeopardizing emotional relationships;

- The emergence of addiction, resulting in degradation of social characteristics of a personality; and

- Larger number of virtual friends in comparison to real-life friends (Baldiņš, 2016).

In its traditional sense, socialization is "a process whose content is determined by the assumption and development of the entire totality of social influences of the world civilization level, culture, and universal human qualities"; it also involves the "development and self-change of a person in the process of the assumption of norms, values, attitudes, and social interaction of a person with emergent, relatively directed and purposefully created living conditions at all age stages" (Mudrik, 2011). Socialization is carried out in interconnections, interactions, and interrelations with other people. It is characterized by the demonstration of a diverse emotional relationship of a person to other people, or to themselves, as a member of the society (Pronina, 2012). The authors of the present research declare that at present, socialization is considered as a process of assumption (development) of social experience, which is influenced by micro factors, such as family, school, and Internet technologies (digital technologies); it is carried out in a mixed real, natural, or traditional (real interaction, communication) and a virtual online or offline environment. Therefore, digital socialization is the process of assumption and development of social experience in a mixed social and offline/online reality (social and digital space) through the participation and reproduction of such an experience in social interactions, online contexts, and network communities.

Primary school age is a new period in a child's life involving personal and social changes, namely: a new social situation of development, a new type of leading educational activity, the formation and development of "self-concept," the development of broad social motives 
(Bozhovich, 2008), and the formation of primary social maturity (Gudzovskaya, 2014). Being in a new social situation of development, primary school children demonstrate the following indicators of socialization: striving for academic success and achievement; gaining recognition and popularity among peers and the wider public; demonstrating social activity; and establishing interpersonal relationships with classmates (Pronina, 2012). In the framework of natural, real relationships with classmates, younger students often conflict, do not gain recognition or popularity among classmates, and have difficulties with self-presentation and self-expression. The acceptance of the Internet as an agent of socialization is due to the ease of communication and interaction on online platforms. On social networks, such problems disappear, "likes" are used instead of verbal communication, and virtual relationships and friends on Vkontakte appear instead of real relationships and friends. The social space of a younger student narrows. "The natural socialization of a person by means of life context is excluded and replaced by a digital model of socialization, i.e., a state of alienation from the real world and natural social environment and immersion into a digital model of a life context up to the state of "hikikomori'" (Nepomnyaschiy, 2017).

We cannot talk about Internet addiction in primary school age, as it is characteristic of adolescence. According to Maria Namestnikova, Kaspersky Lab expert on the IT security of children, such interaction with the Internet does not imply serious deviations in childhood. Therefore, the term "Internet involvement" is introduced (Chernykh, 2019).

\section{Material and Methods}

An analysis of the structural and substantive characteristics of socialization allows us to regard it as a combination of cognitive, emotional evaluative and conative components with the relevant content. The content of the cognitive component includes moral norms and rules of behavior. The content of the emotional evaluative component comprises various characteristics and ways of establishing socially significant relations and interactions with other people. The content of the conative component includes a child's social and moral behavior and actions (Pronina, 2012). In terms of traditional socialization, for example, the participants master communication rules, such as the rules of speech etiquette. Digital socialization does not comprise such rules, and participants have a free choice in what they do (although they do not always make the right one). They do not see the emotional response of another participant in a virtual contact (except, perhaps, through a Skype contact).

We can identify both negative and positive aspects of digital socialization. The use of online devices, tools, and technologies in schools is seen as being able to promote ' 21 st century' skills, specifically inter personal (e.g., being empathetic, taking others' perspectives, cooperation and collaboration) and intra personal skills (e.g., persistence and self-control) (McNaughton, et al., 2018). However, heavy use of digital media by young children has an adverse impact on their psychological well-being (Bruggeman et al., 2019).

Digital socialization of a personality is not an independent process, which contributes to a complete immersion in online reality. We consider it as a supplement to traditional socialization with diverse degree of attitude, participation and acceptance. The purpose of the study is to identify the formation of the digital socialization components among primary school students with different levels of Internet impact (the level of digital environment impact).

The present study included three stages. At the first stage, the authors tested parents and diagnosed children's Internet addiction in order to reveal the rate of Internet impact (by Kulakova, S.A.). The test contained 20 questions that were supposed to be answered on a five-point scale: 1 means very rarely, 2 - sometimes, 3 - often, 4 - very often, 5 - always. The test diagnosed the existence of three levels of Internet impact on a child: level 1 is low, level 2 - significant and level 3 - high. The test involved 533 parents (mainly mother or father) of primary school children. 
According to the test results, the percentage distribution of children by the level of Internet impact was carried out.

At the second stage, the researchers determined the features and characteristics of the components of digital socialization of primary school children in a mixed natural (real) and online / offline environment. For this purpose, a specially developed questionnaire (Pronina, A.N.) was applied, which consisted of 23 questions (Table 1), aimed at identifying the cognitive component, i.e., application of the rules and norms of behavior and communication (11 questions), emotional component, i.e., the demonstration of social emotions (9 questions), and conative component, i.e., the demonstration of social behavior. Primary school children had to answer each question the following way: I agree (yes), no, I cannot say.

At the first stage of the present research on the Internet influence, 540 parents were involved into survey to determine children's Internet addiction. The experiment on the study of the characteristics of digital socialization involved 316 primary school students of the 1st, 2nd, and 3rd year aged 7 to 9 . The survey was conducted with a written consent from the students' parents. Children answered a questionnaire individually in the presence of a psychologist. All the results were recorded in a table; the obtained data were processed by means of the primary analysis. The third stage included a qualitative descriptive analysis of the digital socialization of primary school students with a different level of Internet involvement.

\section{Results}

The survey among the parents to determine children's Internet addiction according to Kulakova's method revealed approximately the same percentage of high (28\%) and low (25\%) levels of Internet involvement for primary school children (Figure 1).

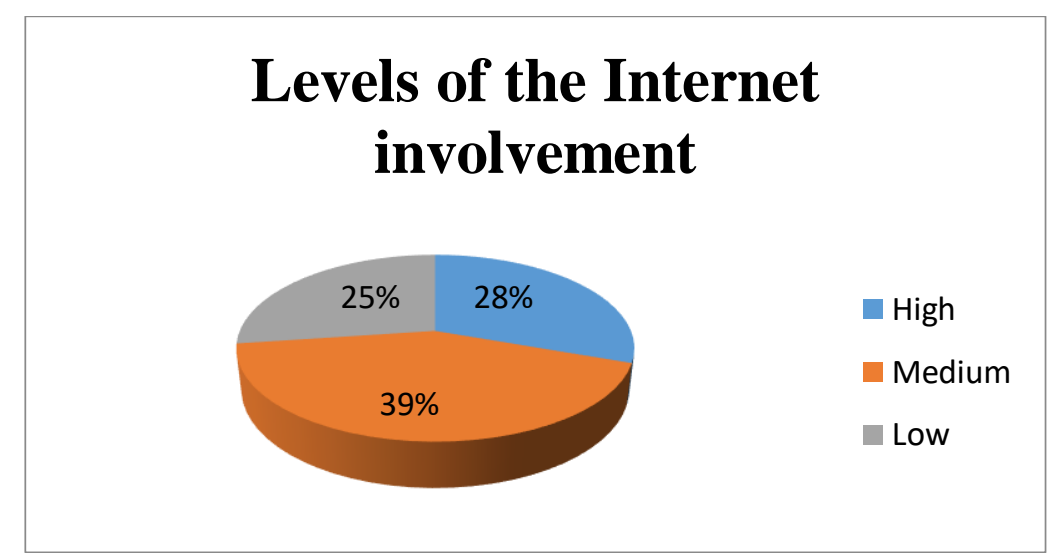

Figure 1. Percentage distribution of primary school children by the levels of Internet involvement.

The authors introduced the results of the formation of each component of digital socialization of primary school students. It was revealed that $100 \%$ of primary school children of all levels of the Internet involvement in natural real communication consider it necessary to comply with the rules of cultural behavior and the etiquette (Table 1).

According to the survey, a large percentage of the tested students with a low level of Internet involvement consider it necessary to follow the rules of a cultural behavior for the communication on the Internet, while in the group of medium and high Internet involvement, the number of positive answers decreases. Despite the understanding of the necessity to keep up to a cultural behavior in Internet communication, only students with low Internet involvement follow these rules. However, a small percentage of them prefer replacing normative words and phrases 
with special characters or other vocabulary. Most students with high Internet involvement use special signs for online communication.

Primary school children in real traditional communication keep up etiquette norms. They congratulate friends on holidays and other events. At the same time, most students with low Internet involvement prefer personal greetings. This index decreases for the students with medium and high levels of Internet involvement. Thus, the congratulations through social networks prevail.

All primary school students that were under test, considered it necessary to follow the etiquette and congratulate friends online, although the congratulations differed in the ways of expression among the students of different levels. Students with low Internet involvement use self-prepared text. However, the others choose ready-made image tools for congratulations, i.e., pictures or texts.

In real communication, students of different levels of Internet involvement express their respect, approval, and recognition to their friends. They also consider it necessary to do this in online communication. However, the demonstration of such communication forms by means of a text message is mostly characteristic of primary school students with low level of Internet involvement. Most students with medium and high level of Internet involvement use digital (computer) tools

Table 1.

Percentage ratio of the formation of the cognitive component of digital socialization of primary school students with different levels of Internet involvement

Cognitive component

Yes $\quad$ No $\quad$ I cannot say

Questions

1. Do you follow the rules of a cultural

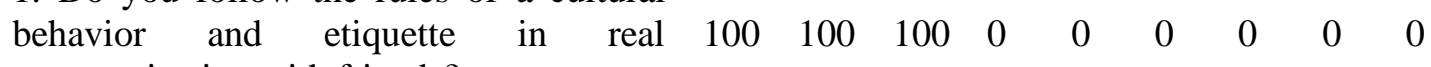
communication with friends?

2. Is it necessary to follow the rules of etiquette (say hello, goodbye, sorry, etc.) discussing a topic in the VKontakte group and on other social networks?

3. In communication with friends online, do you mostly:

- use the forms of civility, i.e., hello, goodbye, sorry, etc.?

- use other vocabulary accepted for online communication (such as ok), use emoticons, or other signs?

4. Do you congratulate your friends on $\begin{array}{llllllllllll}\text { various dates and events in real } & 92 & 76 & 70 & 8 & 24 & 30 & 0 & 0 & 0\end{array}$ communication?

5. In real communication with friends, do you congratulate them on various dates and events in the following ways:

- Do you talk and congratulate personally?

\section{$\begin{array}{lllllllll}66 & 45 & 35 & 12 & 38 & 54 & 22 & 17 & 11\end{array}$ \\ 刍主寻寻主寻主主

$\begin{array}{lllllllll}100 & 100 & 100 & 0 & 0 & 0 & 0 & 0 & 0\end{array}$

(6)

(6)

$\begin{array}{lllllllll}70 & 58 & 33 & 5 & 4 & 2 & 0 & 0 & 0 \\ 22 & 35 & 64 & 3 & 3 & 1 & 0 & 0 & 0 \\ 92 & 76 & 70 & 8 & 24 & 30 & 0 & 0 & 0\end{array}$

$\begin{array}{lllllllll}64 & 32 & 24 & 5 & 13 & 4 & 0 & 0 & 0\end{array}$


- Do you use social networks, the Internet? 6. Is it necessary to congratulate the participants of your group (or another group) on VKontakte (or other social networks) on various dates and events?

7. Do you congratulate the participants of your group (or other group) on VKontakte (or other social networks) on various dates and events?

8. To congratulate the participants of your group (or other group) on VKontakte (or other social networks) on various dates and events, do you:

- use a self-prepared text message?

- download congratulations, pictures from the Internet?

9. Do you show (express) respect, approval, and recognition to your friends in real communication?

10. Is it necessary for your group (or other group) on VKontakte (or other social networks) to show (express) respect, approval, and recognition to the friends?

11. To show (express) respect, approval, recognition to the friends, your group (or other group) on VKontakte (or other social networks), do you:

- use a self-prepared text message?
- download congratulations and pictures from the Internet, or click "like"?
28

28

48

63

$\begin{array}{lllllllll}54 & 35 & 28 & 4 & 12 & 0 & 0 & 0 & 0 \\ 36 & 50 & 72 & 5 & 3 & 0 & 0 & 0 & 0 \\ 62 & 55 & 58 & 16 & 20 & 21 & 22 & 25 & 21 \\ & & & & & & & & \\ & 60 & 71 & 26 & 28 & 19 & 30 & 12 & 10\end{array}$

Note: LLIV - low level of Internet influence; MLIV - medium level of Internet influence; HLIV - high level of Internet influence

The results of a survey among primary school students to identify the characteristics of the formation of the emotional component of digital socialization are introduced in Table 2. For all groups of the school students under study, the survey showed the formation of emotional response in real communication with traditional forms and means of expression. Despite a large percentage of affirmative answers to the questions related to the necessity to demonstrate the emotional response on the Internet, negative answers and those indicating difficulties in answering (I cannot say) appeared in all groups of the Internet involved students. Most primary school students showed emotional empathy to other participants of Internet communication. At the same time, most schoolchildren with low Internet involvement tried to do this in a traditional way (selfprepared text message). In addition, we observed the increase in using special templates and pictures (signs) from the Internet among the students with medium and high levels of the Internet involvement.

It was revealed that, approximately half of the primary school students of all groups show negative emotions for other people in real traditional communication. High level of the Internet involvement of the schoolchildren contributes to the increase in the affirmative answers to the question about the possibility of the demonstration of negative emotions against other people in the informational environment (Internet). It was found that half of the schoolchildren with a low level of Internet involvement did not show negative emotions towards the members of the Internet community. However, the percentage of participation in such events increased in other groups. 
Most students with medium and high levels of Internet involvement used special templates, pictures, and signs to express negative emotions and feelings in relation to other network participants. The students with a low level of involvement used self-prepared text messages.

Table 2.

Percentage ratio of the formation of the emotional component of digital socialization of primary school students with different levels of Internet involvement

Emotional component

\begin{tabular}{llll}
\hline Questions & Yes & No & I cannot say
\end{tabular}

1. Do you show an emotional attitude

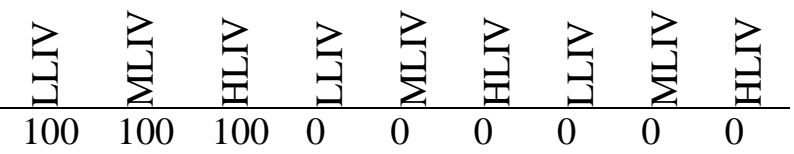
(feelings) about positive or negative events in your friends' life in real communication?

2. In real everyday communication, do you show emotions and feelings about positive or negative events in your friends' life through:

- personal (verbal) demonstration?

- social networks, the Internet?

3 . Is it necessary to show, demonstrate emotions about positive and negative events that happen with the users of your VKontakte group in an online communication?

4. Do you show emotions about positive and negative events happening with your VKontakte group users?

5. To show any emotions and feelings to the members of the VKontakte group, do you:

- use a self-prepared text message?

- use any special templates (everything will be alright, everything will be ok, etc.)?

6 . Do you show negative emotions (hatred, aggression, threats) towards your friends and acquaintances in real communication? 7. Is it possible to show negative emotions (hatred, aggression, threats) towards the

$\begin{array}{lllllllll}85 & 77 & 64 & 3 & 3 & 8 & 0 & 0 & 0 \\ 12 & 20 & 28 & 0 & 0 & 0 & 0 & 0 & 0 \\ 64 & 74 & 80 & 12 & 25 & 20 & 24 & 0 & 0\end{array}$
other members of the VKontakte group in online communication?

8. Do you show (did you show) negative emotions (hatred, aggression, threats) towards the other participants of the VKontakte social network in online communication?

9. To show negative emotions (hatred, aggression, threats) towards the other VKontakte participants in online communication, do you:

$\begin{array}{lllllllll}64 & 52 & 44 & 9 & 11 & 16 & 5 & 0 & 0 \\ 22 & 37 & 40 & 0 & 0 & 0 & 0 & 0 & 0 \\ 54 & 49 & 51 & 32 & 20 & 30 & 14 & 21 & 19 \\ 44 & 60 & 77 & 31 & 28 & 25 & 23 & 12 & 0 \\ & & & & & & & & \\ 34 & 52 & 70 & 50 & 48 & 30 & 16 & 0 & 0\end{array}$




$\begin{array}{llllllllll}\text { - use a self-prepared text message? } & 45 & 37 & 26 & 5 & 10 & 8 & 8 & 0 & 0\end{array}$

- use any special templates, pictures from $\begin{array}{llllllllll}20 & 50 & 64 & 10 & 3 & 2 & 12 & 0 & 0\end{array}$

the Internet?

Note: LLIV - low level of Internet influence; MLIV - medium level of Internet influence; HLIV - high level of Internet influence

The results of a survey among primary school students with different levels of Internet involvement, characterizing the formation of the conative component of digital socialization, are introduced in Table 3. It was revealed that in real everyday relationships, all the surveyed students $(100 \%)$ provide help and support to their friends in various life situations, using mainly personal effective participation (they came, helped, gave advice). Additionally, students with different levels of Internet involvement consider it necessary to show and provide such a support on social networks and Internet communication. They participated personally in the provision of such an assistance, using self-prepared text messages (appeal, recommendation).

Primary school students with various levels of Internet involvement admitted that they did negative things to their friends and acquaintances (betrayed, humiliated, remained indifferent, threatened) in real life. However, most of them rather prefer using the Internet for this purpose than direct personal interaction. Even schoolchildren with a low level of Internet involvement tend to use informational means for negative acts, and not traditional ones. It is worth highlighting that an increase in the level of Internet involvement contributes to the necessity and possibility to commit negative acts on the Internet by means of special informational technologies (templates, pictures from the Internet).

Table 3.

Percentage ratio of the formation of the conative component of digital socialization of primary school students with different levels of Internet involvement

\begin{tabular}{llll}
\hline Conative component & & & \\
\hline Question & Yes & No & I cannot say \\
\cline { 2 - 3 }
\end{tabular}

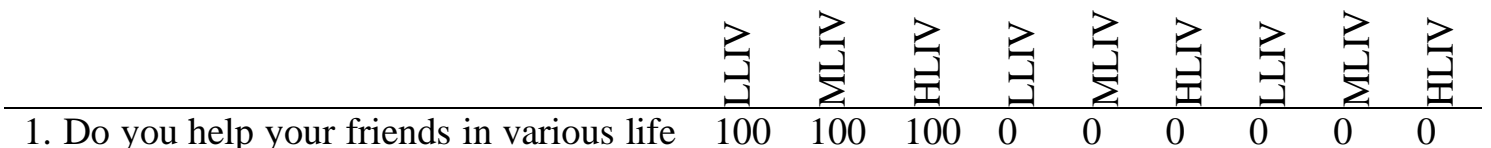
situations (in studying, preparation for sports competitions and exhibitions, etc.) in real life, in everyday relationships?

2. To help somehow and support your friends in real life, in everyday relationships, did you: organize, give an advice)?

- use the Internet?

$\begin{array}{lllllllll}74 & 62 & 55 & 3 & 4 & 2 & 0 & 0 & 0 \\ 20 & 32 & 40 & 3 & 2 & 3 & 0 & 0 & 0 \\ 65 & 68 & 87 & 22 & 30 & 10 & 13 & 2 & 3\end{array}$

3. Is it necessary to provide group members and users with help and support on the Internet in various life situations (in studying, preparation for sports competitions and exhibitions, etc.)? 
4. Do you personally help and support (did you help) users of the group in various life situations?

5. What means of Internet communication do you use (did you use) to show support to the group members and users, if they have any problems?

- Do you use personally compiled text message (appeal, recommendation)?

- Do you use any special templates, pictures from the Internet?

6. In real life, did you do any negative things towards your friends and acquaintances (betrayed, humiliated, remained indifferent, threatened)?

7. In real life, did you did any negative things to your friends and acquaintances (betrayed, humiliated, remained indifferent, threatened) using:

- personal talk, appeal?

- the Internet?

8. Is it possible to do any negative things to your friends and acquaintances (betray, humiliate, remain indifferent, threaten) on the Internet?

9. Did you personally do any negative things to your friends and acquaintances (betray, humiliate, remain indifferent, threaten) on the Internet?

10. What means of Internet communication did you use to do any negative things to your friends and acquaintances (betray, humiliate, remain indifferent, threaten) on the Internet?

- Did you use self-prepared text message (appeal)?

- Did you use any special templates, $\begin{array}{llllllllll}34 & 25 & 43 & 12 & 19 & 16 & 18 & 8 & 5\end{array}$
pictures from the Internet?

Note: LLIV - low level of Internet influence; MLIV - medium level of Internet influence; HLIV - high level of Internet influence

\section{Discussion}

The analysis of various research show that the interaction with virtual reality significantly influences the development and socialization of a person, changing social connections and the ways and means of interaction between an individual and the society. Therefore, the ideas about social processes and phenomena were changed. The understanding of both physical and social objects changed, i.e., effective but the insignificant characteristics of the perceived information were emphasized, and non-verbal messages were not recognized. The phenomenon of file thinking appeared, exaltation developed and became a typical feature. Methods and means of interpersonal communication also changed, i.e., emotionally sensual experience was leveled out (Kuzmina, 2018). The authors of the present study have specified these data. In addition, they revealed the features of the various components of digital socialization in a particular age group, namely, primary school students. 
Peculiarities of the cognitive component of digital socialization of primary school children were expressed in the fact that schoolchildren with medium and high levels of Internet involvement did not consider it necessary to observe social norms and rules of behavior in neither online nor offline environment (communication). The authors introduced the idea that this aspect depends on the children's remoteness from real contact and interaction with a specific person. Real communication was substituted with non-contact method on the VKontakte, WhatsApp, or Instagram, pictures, emoticons (graphic emoticons), etc. Domestic researchers studying the teenagers' communication on the Internet highlight a frequent lack of common courtesy (Evseeva et al., 2014). The present study also revealed these patterns.

Among the students with a high level of Internet involvement rather inductive speech genres than etiquette ones prevailed. Thus, there is no basic communicational and behavioral culture in Internet communication. Certain detachment from generally accepted traditional rules of cultural behavior and communication are observed in the online environment. However, a small percentage of primary school students still need to apply the traditional rules and norms of communication.

It is necessary to note that primary school students with a low level of Internet involvement preferred the verbal way of demonstration the etiquette rules and norms (congratulations) both in real communication and on the Internet. This is a characteristic of traditional socialization, which requires conscious filling with social or personal content. The increase in the level of Internet involvement contributes to the substitution of this method with a technological (mechanical), less complicated in social and verbal terms, i.e., pictures, and copied text.

The analysis of the emotional component of digital socialization of primary school children showed that all subjects with different levels of Internet involvement understood the necessity to demonstrate positive emotional attitude (empathy, support, experience in relation to the surrounding people) both in traditional and online communication. In the Internet community, personal inclusion and verbal (written) messages prevailed as the ways of expressing (demonstrating) emotional empathy among primary school students.

It was also noted that an increase in the level of Internet involvement among primary school students contributed to their propensity for the possibility and necessity to demonstrate negative emotions in Internet communication. In addition, there was a tendency to substitute written emotional support in virtual discourse with punctuation marks and emoticons.

The results of the analysis of the conative component of the digital socialization of primary school students showed that a large percentage of subjects preferred helping their friends in various life situations (in studying, preparation for sports competitions and exhibitions, etc.) by means of a self-prepared text message both in real and online communication. The conative component of digital socialization was characterized by a tendency for increasing the percentage of schoolchildren with medium and high levels of the Internet influence that were confident in the necessity to commit negative acts in online communication. The increase in the level of Internet involvement contributed to the use of non-linguistic (paragraphia) means of communication, when committing negative acts on the network. The authors of the present research suggested that such a substitution is very "convenient" for schoolchildren when it is necessary to avoid personal involvement in negative social behavior.

The authors have found out that most of the primary school students with different levels of Internet involvement still tend to use the elements and traditional ways of socialization in the process of digital socialization, especially for the emotional and conative components.

\section{Conclusion}


In the process of digital socialization among primary school students, the increase in Internet involvement contributes to reinterpretation of the necessity to comply with socially significant norms and rules of behavior, for using the means and methods of their demonstration in the Internet interaction with other subjects. Additionally, the majority of primary school students, regardless of the level of Internet involvement, still understand the significance and necessity to demonstrate an emotional attitude and socially significant behavior towards other subjects, as well as traditional ways of expressing such an attitude (personal appeal). However, there are some examples of substitution of typed emotional and behavioral reactions with the human emotions' images (emoticons) in virtual discourse.

The authors of the study declare that Internet technologies have become a part of the younger generation life. However, digital socialization cannot entirely replace the life context of the personality of primary school students with digital models and communication methods. The content, methods, and means of traditional socialization are still remained, indicating the existence of integrated (mixed) socialization.

Education is a two-sided process, which includes training and upbringing. The last, being a synonym for traditional socialization, involves the acceptance of norms of social behavior, personal experience of the relationships between people, and solving the situations of moral choice in social situations. These skills can be mastered rather in the context of direct verbal communication and relationships with classmates, peers, and educators than in the Internet space using digital technologies.

Therefore, primary school teachers should apply a rational combination and balance of the methods and techniques of traditional and digital socialization in the educational process in order to reduce the risks of individualism, isolation from reality, godlessness, and immorality, which are already characteristic of the modern Z-generation.

\section{References}

Baldiņš, A. (2016). Insights into e-pedagogy Concept Development. Procedia - Social and Behavioral Sciences, 231, 251-255.

Bozhovich, L.I. (2008). Personality and its formation in childhood. St. Petersburg: Piter.

Bruggeman, H., Van Hiel, A., Van Hal, G., Van Dongen, S. (2019). Does the use of digital media affect psychological well-being? An empirical test among children aged 9 to 12 . Computers in Human Behavior, 101, 104-113.

Chernykh, A. (2019). Networks are not children toys. Kommersant. Available at: https://www.kommersant.ru/doc/3924355

Evseeva, I.V., Kozheko, A.V., Luzgina, T.A. (2014). Verbal aggression and politeness in an online communication of school students. Contemporary problems of science and education, 1, 343.

Feldstein, D.I. (2003). Socialization and individualization - the content of the process of social growth. Developmental psychology: childhood, adolescence, youth: anthology. Moscow: Academia.

Frolova, T.I., Obraztsova, A.Y. (2019). Media literacy of schoolchildren in a post-transitive society: study results. Theoretical and practical issues of journalism, 8(4), 747-762.

Global Digital Report. (2019). Available at: https://wearesocial.com/global-digital-report-2019

Gudzovskaya, A.A. (2014). Psychology of social maturity: Monograph. Samara: SIPKRO Publishing House.

Kuzmina, K.E. (2018). Changes in the processes of development and socialization of a personality in terms of digital society. Personality in space and time, 7, 71-75.

McNaughton, S., Rosedale, N., Ngaire Jesson, R., Hoda, R., Teng, L.S. (2018). How digital environments in schools might be used to boost social skills: Developing a conditional augmentation hypothesis. Computers \& Education, 126, 311-323. 
Mudrik, A.V. (2011). Human socialization: manual for students. Moscow: Publishing House of the Moscow Psychology and Social Institute.

Nepomnyaschiy, A.V. (2017). The role of digital models of the life context in the process of personality socialization. Culture. The science. Integration, 1(37), 9-15.

Pronina, A.N. (2012). Socialization-individualization of the children of senior preschool age in the context of educational process of the orphanage. Doctor Thesis in Education. Bunin Yelets State University. Yelets.

Soldatova, G.U. (2018). Digital socialization in the cultural-historical paradigm: a changing child in a changing world. Social Psychology and Society, 9(3), 71-80.

Zizek, B. (2017). Digital Socialization? An Exploratory Sequential Analysis of Anonymous Adolescent Internet-Social Interaction. Human development, 60(5), 203-232. 